\title{
DEPRIVATIONS OF THE URBAN POOR IN MULTIDIMENSIONAL CONTEXT IN THE NORTH EASTERN INDIAN STATE OF MIZORAM
}

\author{
James L.T. Thanga ${ }^{1}$ \\ Associate Professor, \\ Department of Economics, \\ Mizoram University.
}

\author{
Joseph Lalremsanga ${ }^{2}$ \\ Research Scholar, \\ Department of Economics, \\ Mizoram University
}

\begin{abstract}
It is now widely accepted that poverty everywhere is no longer a question of lack of income or insufficient calorie intake, it has broadened to include several areas of deprivation such as inadequate housing, health \& nutrition, assets, etc. So, multidimensional poverty index has been developed and used to examine the levels deprivations of people on basic necessities of life. Multidimensional poverty index has been constructed based on the sample survey data to examine deprivation of the poor people living in urban areas of Mizoram, India. It is observed that a quarter of the urban poor are severely deprived, while substantial proportion of the poor can easily fall back to severe deprivation with a slight change in their access to basic necessities of life.
\end{abstract}

KEY WORDS: Multidimensional Poverty Index, Deprivation, Urban Poverty, Assets, Standard of Living, Health \& Nutrition, Financial Inclusion.

\section{INTRODUCTION}

According to Amartya Sen (1976), poverty measurement consisted of two fundamental issues determining who is the poor and construction of an index to measure the extent of poverty. Poverty has traditionally been measured in one dimension, usually income or consumption (Santos and Alkire, 2011). The total monetary value of the minimum requirement for healthy life, like food, fuel, light, clothing, housing, etc. is usually accepted to be poverty line. However, this unidirectional method had showed its distinct limitation due to its immoderate simplicity (Wang and Qian 2015). Unidimensional methods require a single dimensional variable and a single cutoff, but place no a priori restrictions on how the resource variable has been constructed (Alkire and Foster, 2011).

In the mid-1970s that 'basic needs' approach posited that development concerns should be focused on providing people their basic needs, as opposed to merely increasing their income (Afonso, et al. 2015). A list of basic needs may be determined, along with minimum satisfaction, for poverty identification. Contrasting with the income method, the direct method assesses human deprivation in terms of shortfalls from minimum levels of basic needs per se, instead of using income as an intermediary of basic needs. As such, it is now widely accepted that poverty everywhere is no longer a question of lack of income or insufficient calorie intake, it has broadened to include several areas of deprivation such as inadequate and unsafe housing, insecure workplaces, debilitating environments, etc. (Siddiqui, 2014). With the increasing understanding that poverty is of multidimensional and dynamic natures, many studies had responded with new measures and tools that comprehensively measure poverty to the strong demands of governments and international communities (Wang and Wang, 2016).

Inadequate infrastructures, spatial location of slums, and negative stigma towards the urban poor have caused severe constraints in their employment opportunities (Baker, 2008). Today, the issues of urban poverty have emerged as a complex 
multidimensional phenomenon that cannot be left neglected any further. Chaudhry et. al. (2006) emphasized that urban poverty and governance are the contemporary issues in the subject of economic development particularly for the developing countries.

\section{MULTIDIMENSIONAL POVERTY INDEX}

The Multidimensional Poverty Index (MPI) has been developed by Alkire and Santos (2010) for the 2010 Human Development Report. It replaced the Human Poverty Index (HPI) developed by the United Nations in 1997. It is an index of acute multidimensional poverty and is based on the Alkire and Foster (2011) dual cut-off method for poverty specification (Dotter and Klasen, 2014). Three dimensions identified to be included in the multidimensional poverty index (MPI) are health, education, and the stand of living (Dotter and Klasen, 2014). Santos and Alkire (2011) proposed 10 indicators: two for health (nutrition and child mortality), two for education (years of schooling, school attendance), and six for living standard (cooking fuel, sanitation, water, electricity, floor and assets). Each of these indicators are given proper weightage in the calculation of the aggregate index, called multidimensional poverty index (MPI). The global Multidimensional Poverty Index (MPI) is measured annually to depict the complexities of the collective and individual lives of the poor in different countries, and presented in the Human Development Reports (GMPI, 2020)

The MPI is normally calculated at the country level using globally comparable data and it compares the situation of countries with respect to acute poverty. The Human Development Report 2011 presented the global MPI for 109 countries. At the same time, the MPI is a very versatile methodology and there are multidimensional poverty measures that have been created by adapting the method upon which the MPI is based to better address local realities, needs and the data available (Santos and
Alkire, 2011). Therefore, new methods may be needed to be introduced to identify the complex and multidimensional measure through which poverty may be viewed and understood (Wang and Wang, 2016). Accordingly, attempt is made in this study to study urban poverty in multidimensional context using specifically constructed and adapted MPI to suit the available information obtained from the sample survey and to better address the local conditions of the study area, while internationally adopted indicators are kept in view while selecting sub-indicators.

\section{METHODOLOGY}

Data Source: There are 23 notified urban towns, and of these urban centres, the state capital, Aizawl city is the largest and accounted for more than $51 \%$ of the all the urban population in the state. It is the only urban centre which have municipality in the State having 20 Wards and 83 localities. Accordingly, Aizawl city is the purposively selected area for this study. The primary data was collected using a scheduled questionnaire from the sample households. Selection of sample households was undertaken in two stages, selection of sample localities and sample respondents. Sample respondents from each selected locality was undertaken using the official BPL as sampling frame. The survey covered 405 poor households from 11 localities.

Analytical Method: The MPI analysis undertaken in this study may not be comparable with other studies because this specifically designed MPI is used to examine the extent and nature of deprivation prevailing among the poor in urban areas of Mizoram, rather than estimating the headcounts of multidimensional poor. Four major indices with 36 sub-indicators are constructed based on the sample information, namely standard of living, assets, health \& nutrition, and financial inclusion. Sub-indicators in each of the four indices and their respective weightage are given in Table-1.

\section{Table-1: Selected Indicators of the Multidimensional Poverty}

\section{Standard of Living \{maximum: 11 \}}

Structure of dwelling house $\{0$-thatch, 0.5 -semi pucca, 1 -pucca\}

Floor surface per person (minimum of 10 sq.m/person*) $\{0$ - below, 1-above $\}$

No. of room (s) in the dwelling house $\{0-1$ room, 1 -more than 1 rooms

Toilet status $\{0$ - open defecation, 0.25 - public toilet, 0.5 pit latrine, 1- septic tank\}

Whether the toilet is attached in the house $\{0-$ no, 1 -yes $\}$ Separate/dedicated electric connection $\{0$ - no, 1 - yes $\}$

\section{Assets \{maximum: 16\}}

Ownership status of living house $\{0$ - rented, 3 owned

Whether the household possess land other than living house $\{0$ - no, 2-yes

Whether any member have mobile phone $\{0-$ no, 1 -yes

The family have pressure cooker $\{0$ - no, 1 -yes $\}$

Water Filter $\{0$ - no, 1-yes $\}$

The family have Television $\{0-$ no, 1 -yes $\}$ 
Main source of water $\{0$ - other, 0.5 - shared connection, 1 - pipe water connection $\}$

Adequacy of drinking water supply $\{-$ no, $1-$ yes $\}$ Disposal of household waste $\{0$-open, 1-through municipality\}

Whether segregate household waste $\{0$-no, 1-yes $\}$

Any family member having upto high school education (completed 9 yrs. of schooling)** $\{0$-no, 1-yes $\}$

\section{Health \& Nutrition \{maximum: 8\}}

Visit hospital at least once during last one year for checkup (excluding maternity \& medical emergency) $\{0$ no, 1-yes\}

Visit Private Clinic at least once during last one year for checkup (excluding medical emergency) $\{0$ - no, 1-yes $\}$

Visit Private Laboratory at least once during last one year for checkup (excluding medical emergency) $\{0-$ no, 1 yes $\}$

All children are vaccinated $\{0-$ no, 1 -yes $\}$

Enrolled in state government health care scheme $\{0-$ no, $1-$ yes $\}$

Enrolled in central government health care scheme $\{0$ no, 1-yes?

Have two square meals in a day $\{0-$ no, 1 -yes $\}$

Enrolled under Food Security Act or Poor Scheme for Food Supply (AAY \& PHH) $\{0$ - no, 1-yes $\}$

*as given in Mastrucci \& Rao (2017) and ** Rao \& Min (2018)
The four deprivation indices are simply aggregated to find out the overall deprivation index, called the Multidimensional Poverty Index (MPI), for the study area. Given the nature and implication of all indicators considered for each deprivation index, there would be no difficulty for normal households, which have already enjoyed decent standard of living, to attain $100 \%$ score. At the same time, indicators like house and land may be difficult to have for many poor families. Taking these factors into consideration, it is assumed that the poor households should attain at least $75 \%$ of the total score in all the indicators to ensure attainment of decent living and any score below it would mean deprivation in varying degrees. Thus, the sample households were accordingly classified into three groups of deprivation viz. severe $(<50 \%)$, moderate $(50-75 \%)$ and better off $(75 \% \&<)$ according to their score as a percentage of the maximum MPI.
The family have LPG Connection $\{0-$ no, 1 -yes $\}$

The family have Refrigerator $\{0-$ no, 1 -yes $\}$

The family have Washing Machine $\{0-$ no, 1-yes $\}$

The family have Steel Almirah $\{0$ - no, 1-yes $\}$

The Family have Computer set $\{0$ - no, 1-yes $\}$

The Family have Two Wheeler vehicle $\{0-$ no, 1 yes\}

The Family have other vehicle $\{0-$ no, 1 -yes $\}$

\section{Financial Inclusion \{maximum: 4\}}

Whether any one of the family members have bank account $\{0$ - no, 1-yes $\}$

Whether operate the account regularly by making monthly deposit $\{0$ - no, 1 -yes $\}$

Received credit/cash assistance from the government during last 3 years. $\{0$ - no, 1-yes $\}$
Ever taken loan from any bank $\{0$ - no, 1 -yes $\}$

\section{RESULTS \& DISCUSSIONS}

Synchronizing the index scores with the threshold deprivation level established for the study as above, the status of multidimensional deprivation of the urban poor in Mizoram on the four indices were determined and presented in the Table-2. It is observed that only $7.2 \%$ of the poor families in the study area are in the categories of severely deprived from decent standard of living. With regards to the access to assets, as much as $36.8 \%$ are severe deprived At the same time, $55.5 \%$ of the households fall between $50-75 \%$ in the deprivation index, while only $7.4 \%$ of households that could cross $75 \%$ in the deprivation index were categorized as relatively better off. The status on health and nutrition shows $43.2 \%$ of the households falling severe deprived with $50 \%$ in the range of score $50-75 \%$, called moderate. As against this, as little as $5.9 \%$ that could cross $75 \%$ of the score in the deprivation index to be categorized as relatively better off families. It is thus clear that nearly half of the urban poor experience severe inability to access health and nutrition. 
Table-2: Estimate of Deprivation using among urban poor using MPI sub-indices

\begin{tabular}{|lll|lll|}
\hline Deprivation Level & Frequency & Percent & $\begin{array}{l}\text { Deprivation } \\
\text { Level }\end{array}$ & Frequency & Percent \\
\hline $\begin{array}{lllll}\text { 1. Standard of Living } \\
\text { Severe }\end{array}$ & & 2. Assets & & \\
Moderate & 29 & 7.2 & Severe & 149 & 36.8 \\
Better Off & 196 & 48.4 & Moderate & 226 & 55.8 \\
Total & 180 & 44.4 & Better Off & 30 & 7.4 \\
& 405 & 100 & Total & 405 & 100 \\
3. Health \& Nutrition & & & & & \\
Severe & 175 & 43.2 & Severe & 289 & 71.4 \\
Moderate & 206 & 50.9 & Moderate & 107 & 26.4 \\
Better Off & 24 & 5.9 & Better Off & 9 & 2.2 \\
Total & 405 & 100 & Total & 405 & 100 \\
\hline \hline
\end{tabular}

Source: Computed from data of Field Survey 2020

The tabulation of the financial inclusion index shows $26.4 \%$ of households clustered between $50-75 \%$ in the deprivation level, indicating their moderate access to financial inclusion. There was just handful of households i.e. $2.2 \%$ that could cross $75 \%$ in the deprivation index to qualify for the relatively better off category. On the other hand, a disproportionate $71.4 \%$ of households fall below $50 \%$ in the deprivation index, which means that the ability to have access to financial services for nearly three quarters of the urban poor is severe or critical.
The aggregate of the above four indices, called multidimensional poverty index (MPI) or total deprivation index, is presented in Figure-1. The average score of the sample households in the MPI turned out to be 21.26 , which is $54.51 \%$ of the maximum possible score. The standard deviation of 3.55 (i.e. $9.1 \%$ of total points) indicate as much as $68 \%$ of the urban in the study areas are within the score range of $43.41 \%$ to 63.61 .

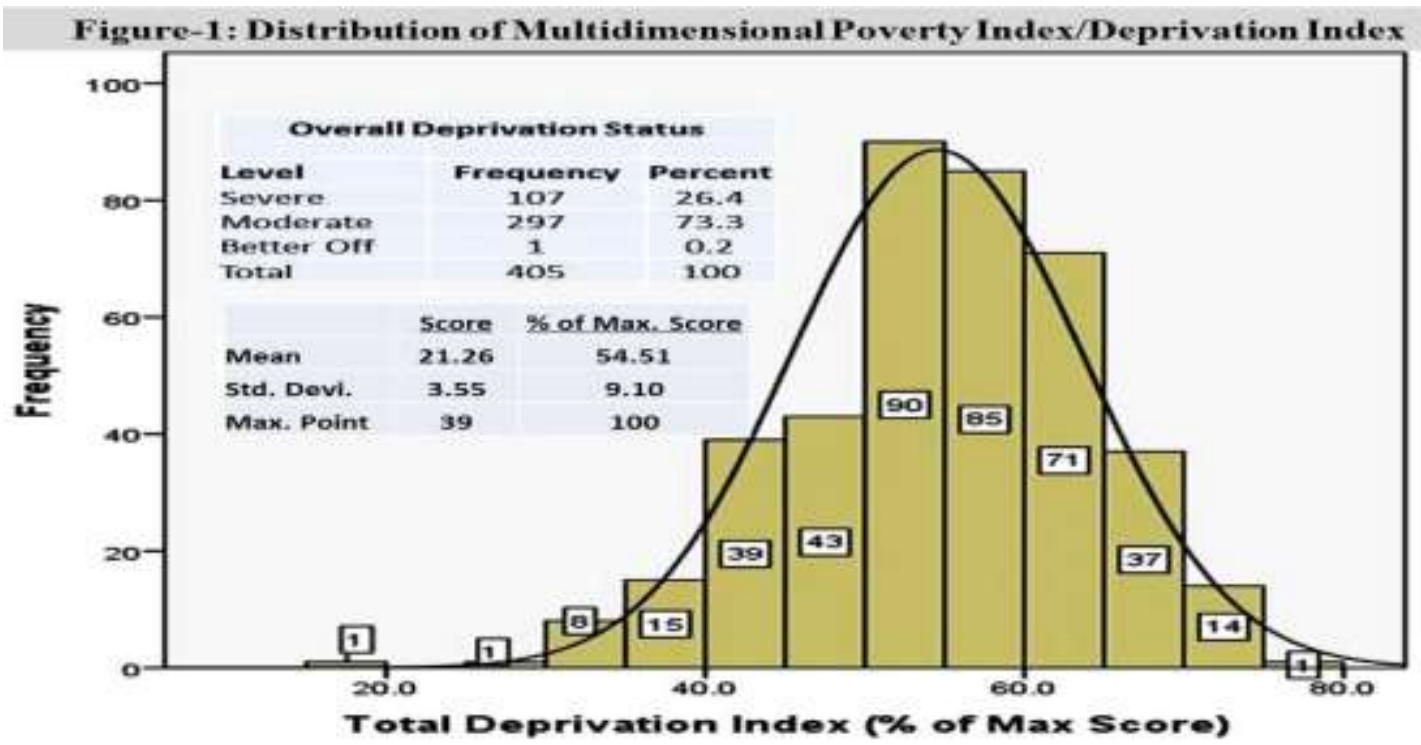

Classification of the households in different levels of deprivation given in Figure- 1 shows that $26.4 \%$ are severely deprived, and $73.4 \%$ moderate deprived, while only 0.2 percent could be considered as better off. It is noteworthy that while a quarter of the urban poor households or $26.4 \%$ are severely deprived, and even those that are moderately deprived are clustered around the border of $50 \%$ 
scores, which is the cut-off point for severe deprivation. That is, as much as $22.2 \%$ could fall to the category of severe deprived if the cut-off point is increased even by $5 \%$.

In order to find the relationships between the various deprivation indices, correlation coefficient between each pair of the index are calculated based on the scores of the households on these indices. In addition to the correlational test, Chi-square statistic is also calculated using cross tabulation of the pair of indices each were grouped by attributes of severe, moderate and better off. The Chi-square test give us the significance of relationship based on frequency cross tabulation, while correlation gives the direction of the relationship (positive or negative). The result is presented in Table-3.

Table-3: Relationship Between Different Deprivation Indices

\begin{tabular}{|c|c|c|c|c|}
\hline \multirow{2}{*}{$\begin{array}{l}\text { Sl. } \\
\text { No. }\end{array}$} & \multirow[b]{2}{*}{ Compared Variables } & \multicolumn{2}{|c|}{ Chi-Square } & \multirow{2}{*}{$\begin{array}{l}\text { Pearson } \\
\text { Correlation }\end{array}$} \\
\hline & & Value & sig. level & \\
\hline 1 & Standard of Living and Assets & $36.88 * *$ & 0.000 & $0.311 * *$ \\
\hline 2 & Standard of Living and Health \& Nutrition & 4.95 & 0.292 & -0.031 \\
\hline 3 & Standard of Living and Financial Inclusion & $20.3^{* *}$ & 0.000 & -0.016 \\
\hline 4 & Assets and Health \& Nutrition & 3.36 & 0.499 & 0.037 \\
\hline 5 & Assets and Financial Inclusion & $11.65^{*}$ & 0.020 & $0.114^{*}$ \\
\hline 6 & Health \& Nutrition and Financial Inclusion & 3.41 & 0.492 & 0.032 \\
\hline
\end{tabular}

It is observed from Table-3 that there is significant and positive correlation between standard of living and possession or access of the assets by the poor households in urban areas. Thus, those who have better command on the assets are the ones who enjoyed better standard of living and vice versa. Notably, there is positively significant correlation between household status on financial inclusion and their possession of assets.

\section{CONCLUSIONS}

Urban poverty is a phenomenon which is multidimensional in nature. Therefore the manifestation can vary widely depending upon the region, culture, people, society and their economic conditions. Due to this multifaceted nature there can be no single solution to address the problems of urban poverty. Based on the analysis undertaken in this paper, the following points may be noted. Firstly, of the four sub-deprivation indices, the urban poor families have fairly better performance on the standard of living as only $7.2 \%$ are considered severely deprived. The lesser deprivation of urban poor from decent standard of living is mainly due to the good educational attainment, more living rooms, separate toilet (septic tank), proper waste disposals, and availability of adequate and safe drinking water for most families. It may be noted that the state of Mizoram is one of the most literate state and is already declared Open Defecation Free (ODF). So, it may not be surprising to see relatively better standard of living even for the poor families.

Secondly, grim conditions of deprivations are observed in health \& nutrition and financial inclusion. The main factors that pull down the health $\&$ nutrition index are the inability of the households to seek regular medical checkup and inability to fulfill $100 \%$ vaccination to the children. At the same time, critical factor for financial inclusion index is the holder to maintain regular operation of their account by making deposit and withdrawal, and limited access to institutional credit. The above problems may be addressed by adopting two pronged strategy namely (i) awareness creation on the significance of - regular medical checkup and regular operation of bank account (small savings, etc.); and (ii) public intervention to ramp up vaccination of children, and provision to make the poor have better access to institutional credit.

Thirdly, the significant and positive correlation between financial inclusion and their possession of assets may be interpreted further. The main sub-indicator that increased financial deprivation or compromise financial inclusion is the limited access of the poor to bank loan, while substantial number of families not having land of their own is one of the factors that increase asset deprivation. So, the requirements of security collaterals set by our banking system to the applicants of bank loan have resounding effect on the financial inclusion of the poor people. 
Lastly, the overall deprivation of the poor as given by the distribution of MPI revealed vulnerability of the urban poor to severe deprivation in the study areas. While a quarter of the urban poor are severe deprived, another $22.2 \%$ could fall into this category even by a slight increase in the cut-off point (i.e. 5\%). This may be taken to indicate the vulnerability of the urban poor to severe deprivation. Substantial proportion of the poor can fall back to severe deprivation with a slight change in their access to basic necessities of life.

\section{REFERENCES}

1. Afonso, Helana' LaFleur, Marcelo and Alarcon, Diana (2015), "Multidimensional Poverty", Development Issues No. 3, UN/DESA. Retrieved from

https://www.un.org/en/development/desa/policy/ wess/wess_dev_issues/dsp_policy_03.pdf 19.4.2021

2. Alkire, Sabina and Foster, James (2011), Understandings and Misunderstandings of Multidimensional Poverty Measurement, OPHI Working Paper No. 43. Retrieved from https://www.ophi.org.uk/wpcontent/uploads/ophi-wp43.pdf accessed on 19.04.2021

3. Alkire, Sabina; Jindra, Christoph; Robles, Gisela and Vaz, Ana (2016), Multidimensional Poverty Index - Summer 2016: Brief Methodological Note and Results, Accessed from http://www.ophi.org.uk/wp-content/uploads/MPI2016-Brief-Methodological-Note.pdf on 19.04.2021

4. Dotter, Caroline and Klasen, Stephan (2014), The Multidimensional Poverty Index: Achievements, Conceptual and Empirical Issues, UNDP Occassional Paper. Accessed from http://hdr.undp.org/sites/default/files/mpi_dotter and_klasen.pdf on 19.4.2021

5. Fay, $M$ and Opal, $C$ (2000), Urbanisation withouth Growth. A Not So-Uncommon Phenomenon, World Bank Policy Research, Working Paper WPS 2412; World Bank, Washington DC.

6. Liddle, Brantley (2017), "Urbanization and Inequality/Poverty”, Urban Science, Vol. 1, No. 35. Pp. 1-7.

7. Santos, Maria Emma and Alkire, Sabina (2011), Multidimensional Poverty Index, Training Material for Producing National Human Development Report, OPHI. Accessed from https://www.ophi.org.uk/wp-

content/uploads/MPI-Primer.pdfon 18.4.2021

8. Sen, Amartya (1979), "Issues in the Measurement of Poverty", Scand. J. of Economics 1979, pp.285-307.

9. Siddiqui, Nasrin (2014), Development and Governance: where the mind is without fear, Epaper. Retrieved from https://nasrinsiddiqui.wordpress.com/2014/11/26 /dimensions-of-urban- poverty/\#: :text=Unlike\%20rural\%

20areas\%2C\%20where\%20lack,\%2C\%20educat ion\% 2C\%20security\%20and\%20empowerment. on 15.4.2021

10. Wang, Yanhui and Wang, Baixue (2016), "Multidimensional poverty measure and analysis: a case study from Heichi City, China", SpringerPlus, 5:642. 